\title{
Development of TLR9 agonists for cancer therapy
}

Arthur M. Krieg

Coley Pharmaceutical Group, Wellesley, Massachusetts, USA.

\begin{abstract}
In vertebrates, the TLRs are a family of specialized immune receptors that induce protective immune responses when they detect highly conserved pathogen-expressed molecules. Synthetic agonists for several TLRs, including TLR3, TLR4, TLR7, TLR8, and TLR9, have been or are being developed for the treatment of cancer. TLR9 detects the unmethylated CPG dinucleotides prevalent in bacterial and viral DNA but not in vertebrate genomes. As discussed in this Review, short synthetic oligodeoxynucleotides containing these immune stimulatory CpG motifs activate TLR9 in vitro and in vivo, inducing innate and adaptive immunity, and are currently being tested in multiple phase II and phase III human clinical trials as adjuvants to cancer vaccines and in combination with conventional chemotherapy and other therapies.
\end{abstract}

\section{Introduction}

The innate immune system evolved to detect and respond to infection. In vertebrates, it does this using several families of receptors that detect highly conserved pathogen-expressed molecules that are not expressed by or accessible in host cells (1). One of the best understood of these families is the TLR family of molecules, of which ten have been identified in humans $(2,3)$. Each TLR binds to one or more distinct pathogen-expressed molecules and can function as an "alarm signal" for the immune system, initiating appropriate host immune defenses $(2,3)$. For example, TLR4 detects LPS, a molecule that is specifically expressed by Gram-negative bacteria but not by other organisms. In response to LPS, TLR4 activation induces the secretion of proinflammatory cytokines and chemokines by host immune cells. Consistent with the hypothesis that TLRs are an important component of immune defenses, mice deficient for TLR4 have an increased susceptibility to infection with Gram-negative bacteria $(2,3)$. A synthetic agonist for TLR4, monophosphoryl lipid A, has been developed as a vaccine adjuvant (4), and a synthetic agonist for TLR7, imiquimod, has been developed in a topical formulation approved by the FDA for treatment of genital warts, actinic keratosis, and basal cell carcinoma, but it is also widely used in other conditions (5). This Review focuses on TLR9, which is the only TLR for which a systemically administered specific agonist has shown substantial evidence of antitumor activity in human clinical trials. TLR9 seems to have evolved to detect the unmethylated $\mathrm{CpG}$ dinucleotides that are relatively common in bacterial and viral genomic DNAs but are uncommon in vertebrate genomes and, if present, are highly methylated (6). For therapeutic applications, TLR9 generally is stimulated with synthetic oligodeoxynucleotides containing one or more unmethylated CPG dinucleotides (CpG ODN).

Each TLR has a unique pattern of cellular and tissue expression, which presumably has evolved to serve its role in the detection of different types of pathogens. Among all the TLRs, TLR9 is

Nonstandard abbreviations used: CPG ODN, oligodeoxynucleotide(s) containing one or more unmethylated CpG dinucleotides; HBsAg, HBV surface antigen; IFA, incomplete Freund's adjuvant; KLH, keyhole limpet hemocyanin; MART1, melanoma-associated antigen recognized by T cells 1 ; NHL, non-Hodgkin lymphoma; NSCLC, non-small cell lung carcinoma; ODN, oligodeoxynucleotide; pDC, plasmacytoid DC; PS, phosphorothioate; PS ODN, ODN that have a nuclease-resistant phosphorothioate backbone.

Conflict of interest: A.M. Krieg is a founder and employee of and shareholder in Coley Pharmaceutical Group and has a financial interest in the development of TLR9 agonists for cancer therapy.

Citation for this article: J. Clin. Invest. 117:1184-1194 (2007). doi:10.1172/JCI31414. thought to have the narrowest expression profile; among resting human immune cells, B cells and plasmacytoid DCs (pDCs) seem to exclusively express TLR9 (reviewed in ref. 2). pDCs are extremely important cells in host defense, as they produce most of the type I IFN that is made in response to viral infection and that is essential to control viral replication and to promote the development of an immune response to eradicate infected cells and prevent recurrence (7). In contrast with this limited expression of TLR9 in humans, B cells, monocytes, and probably all DC subsets express TLR9 in mice $(2,7)$. Consequently, the mouse immune system produces different cytokines and chemokines when exposed to unmethylated $\mathrm{CPG}$ motifs, making it exceedingly difficult to predict the effects of TLR9 activation in humans by extrapolating from results with mice.

Native DNA, which has a phosphodiester backbone (Figure 1), is rapidly degraded in vivo by nucleases that are present in serum and within cells. So investigations of TLR9 stimulation in animal experiments and human trials generally use synthetic CPG ODN that have a nuclease-resistant phosphorothioate (PS) backbone for improved stability (Figure 1). TLR9 seems to be required for all the immune stimulatory responses to synthetic PS ODN, since there is a complete loss of activity in mice genetically deficient for $\operatorname{TLR} 9(6,8,9)$. However, native DNA can activate immune cells through both TLR9 and one or more TLR9-independent pathways if the DNA is delivered into the cells by transfection (10-12). TLR9 also is not required for the induction of the immune responses elicited by DNA vaccines (13). This Review focuses on the applications in cancer therapy of synthetic CPG ODN that, unless otherwise specified, have PS backbones; the term ODN will be used to refer more generally to compounds that elicit effects that are not dependent on the presence of a CPG. In addition, although three families of immune stimulatory CpG ODN with distinct structural and biological characteristics have been described (Table 1) (14) - A-class CpG ODN (also known as D type), B-class CpG ODN (also known as K type), and C-class CpG ODN, here I focus on B-class CpG ODN, which are strong B cell stimulators but induce relatively little $\mathrm{pDC}$ secretion of IFN- $\alpha$, because they are furthest into human clinical development in oncology (Table 1). B-class CpG ODN are the sole class of CpG ODN used in the studies described hereafter, unless otherwise stated.

\section{CpG ODN stimulate Th1-like innate and adaptive immunity}

The immune effects of administering CPG ODN to humans seem to result directly and indirectly from activation of the immune cells that constitutively express TLR9, B cells, and pDCs. CpG 

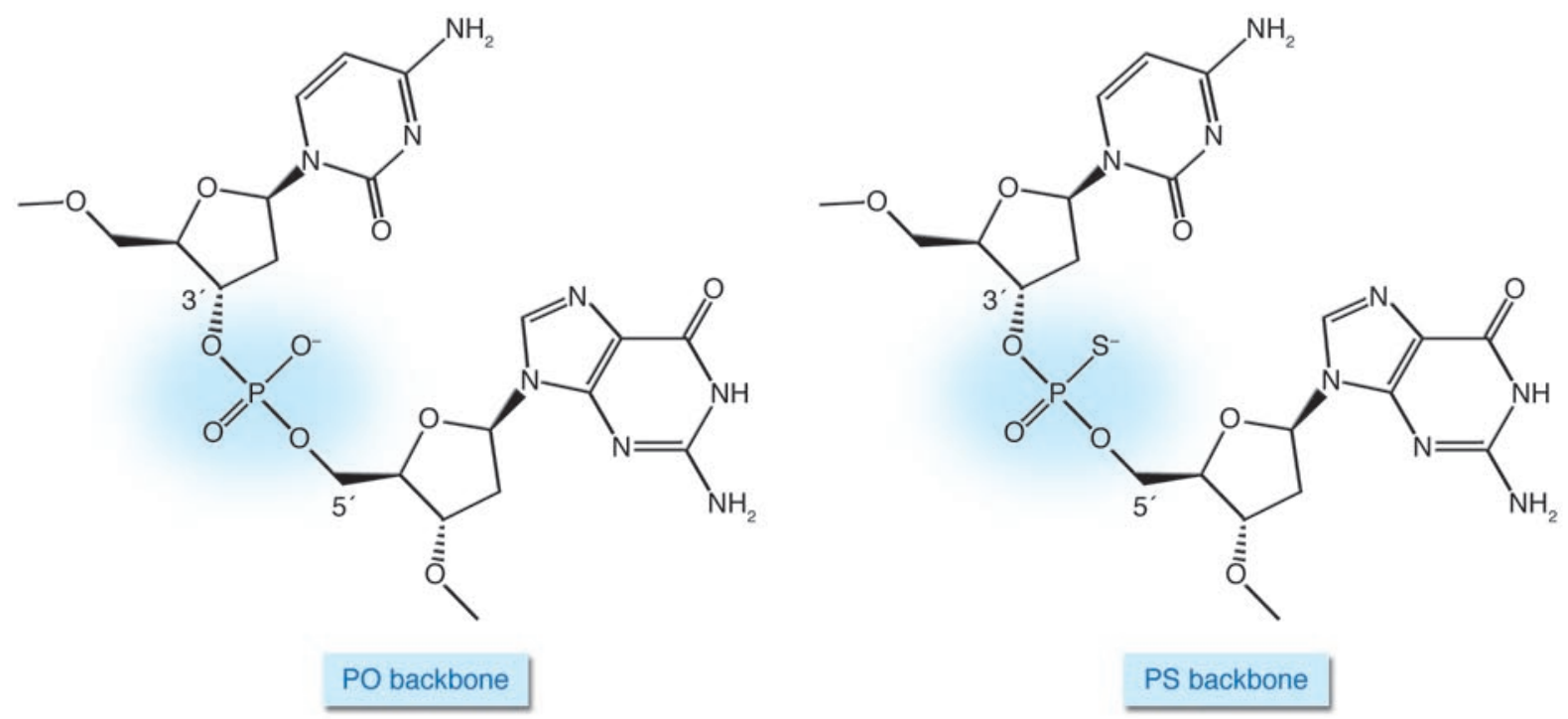

Figure 1

Backbones of native and modified DNA. PS ODN differ from native phosphodiester (PO) DNA ODN only in the substitution of a sulfur for one of the nonbridging oxygen atoms. This change improves the in vivo stability of the ODN from a half-life of a few minutes to about two days for the PS ODN.

ODN require no delivery system in vitro or in vivo - they can simply be administered in saline and are spontaneously taken up by most immune cells, in particular B cells and DCs (ODN uptake is not restricted to TLR9-expressing cells). ODN uptake by lymphocytes is energy and temperature dependent and greatly increased by cell activation; it also seems to be receptor mediated, although the specific receptors remain largely obscure (14). PI3K seems to have some role in ODN uptake, since uptake is diminished by PI3K inhibitors (15). In resting cells, TLR9 seems to reside within the endoplasmic reticulum, but upon CPG ODN uptake, TLR9 translocates into the same endosomal compartment as CPG ODN, thereby allowing binding and initiation of signal transduction $(16,17)$. Chloroquine and other inhibitors of endosomal acidification and/or maturation completely block the immune effects of CpG ODN, demonstrating an essential role for this compartment in the interaction with TLR9 and/or in the initiation of the downstream signal transduction pathways $(16,17)$. The molecular signaling pathways downstream of TLR9 have recently been reviewed in detail and will not be discussed further here (18).

Immune responses can be broadly divided into two types: Th1 and Th2. Th1 immune activation is optimized for fighting intracellular infections such as viruses and involves the activation of NK cells and CTLs that can lyse infected cells. This type of immune activation is the most highly desired for cancer therapy, as the same defenses can be directed to kill tumor cells. In contrast, Th2 immune responses are directed more at the secretion of specific antibodies and are relatively less important for tumor therapy. One of the most notable features of TLR9 activation is the remarkably strong Th1 responses that are triggered (see below).

The immune response to infection or TLR stimulation occurs in two phases: the first to be activated is antigen-nonspecific innate immunity, which is followed by antigen-specific adaptive immunity (Figure 2). TLR9 stimulation with any class of CPG ODN activates innate immunity with a predominantly Th1 pattern of cytokine and chemokine secretion by B cells and pDCs (and by other immune cells that are activated secondarily) (Table 1). In response to TLR9 stimulation, B cells and pDCs also express increased levels of costimulatory molecules (such as CD80 and CD86), TNF-related apoptosis-inducing ligand (TRAIL), which can induce tumor cell death, and CC chemokine receptor 7 (CCR7), activation of which causes cell trafficking to the $\mathrm{T}$ cell zone of the lymph nodes, and show increased resistance to apoptosis (reviewed in ref. 2). Together, these innate immune effects of TLR9 activation can promote tumor regression either directly, through the antitumor activity of factors such as IFN- $\alpha$ and TRAIL, or indirectly, through the activation of NK cell-mediated tumor killing (14).

TLR9-mediated innate immune activation and $\mathrm{pDC}$ and $\mathrm{B}$ cell maturation are followed by the generation of antigen-specific antibody and $\mathrm{T}$ cell immune responses (reviewed in ref. 2). The pDCs activated through TLR9 become competent to induce effective $\mathrm{CD}^{+}$and $\mathrm{CD}^{+} \mathrm{T}$ cell responses (19-23). Both A-class and B-class CPG ODN increase the ability of pDCs to induce antigen-specific $\mathrm{CD}^{+} \mathrm{T}$ cells with a memory phenotype; the B-class $\mathrm{CPG}$ ODN also increase the frequency of $\mathrm{CD}^{+} \mathrm{T}$ cells with a naive phenotype (24). $\mathrm{B}$ cells are strongly costimulated if they bind specific antigen at the same time as TLR9 stimulation (14). This selectively enhances the development of antigen-specific antibodies, suggesting that CpG ODN might be useful as vaccine adjuvants, especially for the induction of strong Th1-biased immunity.

\section{Interactions between Tregs and TLR9}

Tregs are a special subset of $\mathrm{T}$ cells that function to keep other $\mathrm{T}$ cells in check and therefore tend to suppress immune responses. Tregs inhibit antitumor $\mathrm{T}$ cell responses, can be induced by tumors, and might be a major obstacle to effective tumor vaccination and immunotherapy (25). Therefore, there has been much interest in the possible effects of TLR activation upon Treg function. Mouse DCs activated through TLR9 can become resistant to the immune suppressive effects of Tregs in vitro $(26,27)$. In contrast, TLR9 ligands (as well as ligands for TLR2 and TLR4) increase 


\section{Table 1}

$\begin{array}{ll}\text { ODN class } & \text { Example ODN } \\ \text { A-class } & \text { GGgggacgatcgtcgGGGGG } \\ \text { (for IFN- } \underline{\alpha} \text { inducing; } & \text { (also known as ODN 2216) } \\ \text { also called D-type) } & \end{array}$

also called D-type)

Example ODN
GGgggacgatcgtcgGGGGG
(also known as ODN 2216)
TCGTCGTTTTGTCGTTTTGTCGTT

(for $\underline{B}$ cell-activating;

also called K-type)

\section{(also known as CPG 7909}

and PF-3512676)

\section{Structural features \\ Poly G region at the $3^{\prime}$ and/or $5^{\prime}$ ends; usually with a few PS-modified internucleotide linkages at the $5^{\prime}$ and $3^{\prime}$ ends for nuclease resistance, but the center portion of the ODN with the CpG motif(s) must be PO}

Fully PS-modified backbone, no major secondary structure; most important $\mathrm{CpG}$ motif for activating human TLR9 is at the $5^{\prime}$ end
Fully PS-modified backbone, 1 or more 5' CpG motifs; self-complementary palindrome in middle or $3^{\prime}$ end enables formation of duplex or hairpin secondary structure

\author{
Immune effects \\ Induces exceptionally strong pDC \\ IFN- $\alpha$ secretion and moderate \\ expression of costimulatory \\ molecules \\ Induces very little B cell \\ activation \\ Induces very strong B cell \\ proliferation and differentiation \\ Induces $\mathrm{pDC}$ expression of \\ costimulatory molecules and \\ modest IFN- $\alpha$ secretion \\ Induces strong B cell proliferation \\ and differentiation \\ Induces pDC IFN- $\alpha$ secretion \\ and expression of \\ costimulatory molecule
}

Capital letters in ODN sequences indicate 3' PS internucleotide linkage; lower-case letters in ODN sequences indicate 3' PO internucleotide linkage; underlining indicates self-complementary palindromes; bold letters indicate $\mathrm{CpG}$ motifs thought to contribute the most to immune stimulation. PO, phosphodiester.

the proliferation of mouse Tregs cultured in the presence of APCs and CD3-specific antibody (28), and TLR9 activation of purified human $\mathrm{pDCs}$ enhances the generation of Tregs, suppressing naive $\mathrm{T}$ cell responses (29) (Figure 2). To add yet another variable into the biologic interactions between TLR9 and Tregs, the addition of a B-class CpG ODN to in vitro cultures of mouse DCs, Tregs, and naive $\mathrm{T}$ cells results in the production of IL-17, an important mediator of tissue inflammation that can have beneficial or harmful effects, depending on the clinical situation (30).

The in vivo interactions between TLR9 activation and Tregs are likely to be even more complex. Aged mice (18 to 22 months old) have an increased percentage of Tregs in the spleen compared with young mice, but treatment of the aged mice with an s.c. injection of $\mathrm{CpG}$ ODN reduced the percentage of Tregs in the spleen to that seen in young mice, and this was associated with successful rejection of an immunogenic tumor (31). Of note, this Treg-reducing antitumor effect of TLR9 activation was not seen with agonists for TLR3, TLR4, TLR5, or TLR7 (31). Therefore, TLR9 activation can have effects that counter Tregs in vivo, at least in aged mice. Nevertheless, recent studies in young mice clearly demonstrate that TLR9 stimulation does not abrogate the suppressive effects of Tregs. For example, mature DCs pulsed with the antigen keyhole limpet hemocyanin (KLH) were cultured with or without $\mathrm{CpG}$ ODN for 3 hours in vitro and then injected into the footpads of either untreated mice or mice that had been depleted of Tregs (32). Even in the untreated mice (in which Tregs were present), TLR9activated DCs caused a slight increase in antigen-specific IFN- $\gamma$ secretion and almost completely suppressed the Th2 response (IL-4 secretion) to KLH compared with that in the control mice that received non-TLR9 activated DCs pulsed with KLH. However, Treg depletion increased the IFN- $\gamma$ secretion induced by TLR9activated DCs, consistent with the interpretation that the effects of TLR9-activated DCs can be inhibited by Tregs in vivo (32). Similarly, mouse Tregs suppress the antigen-specific $\mathrm{T}$ cell response to footpad or transcutaneous vaccination with a peptide in combi- nation with a CPG ODN adjuvant, suggesting that CPG ODN do not always overcome Treg influences $(33,34)$. The route of administration of $\mathrm{CPG} O \mathrm{ODN}$ is an important variable to consider; i.v. administration of a B-class CPG ODN induces splenic expression of an enzyme linked to the generation of Tregs, indoleamine 2,3dioxygenase (IDO), and results in the suppression of T cell expansion and CTL activity, but s.c. administration of the same CpG ODN has the expected immune stimulatory effects $(35,36)$. Collectively, these studies indicate that, although systemic TLR9 activation induces the expression of many cytokines and chemokines, it also induces counterregulatory feedback mechanisms, including Tregs that might have the biologic effect of avoiding deleterious immune activation or autoimmunity. In mice, intratumoral or s.c. CpG ODN might be more effective than i.v. for inducing antitumor immunity. However, i.v. therapy of previously treated patients with non-Hodgkin lymphoma (NHL) with the B-class CpG ODN PF-3512676, formerly known as CPG 7909 and ODN 2006, led to late clinical responses in 2 of 23 patients (37), indicating potential efficacy of this route of administration in humans (CPG 7909 and PF-3512676 are the same CPG ODN, but CPG 7909 refers to the compound when used as a vaccine adjuvant and PF-3512676 refers to the compound when formulated without an adjuvant). Further studies of the effects of different routes of TLR9 ligand administration on Tregs in humans are needed. Together with the extensive evidence that Tregs contribute to the immune suppression observed in cancer patients $(25,38)$, these reports imply that the efficacy of CPG ODN therapy in cancer might be further increased by the prior depletion or inactivation of Tregs.

\section{TLR9 agonists as Th1 vaccine adjuvants}

The Th1-Th2 character of adaptive immune responses can be determined by the way in which innate immunity is activated (39). The distinguishing feature of $\mathrm{CPG}$ ODN used as adjuvants (i.e., mixed into a vaccine) is their unsurpassed induction of strong Th1 responses. In a mouse study comparing 19 different vaccine adjuvants with two 


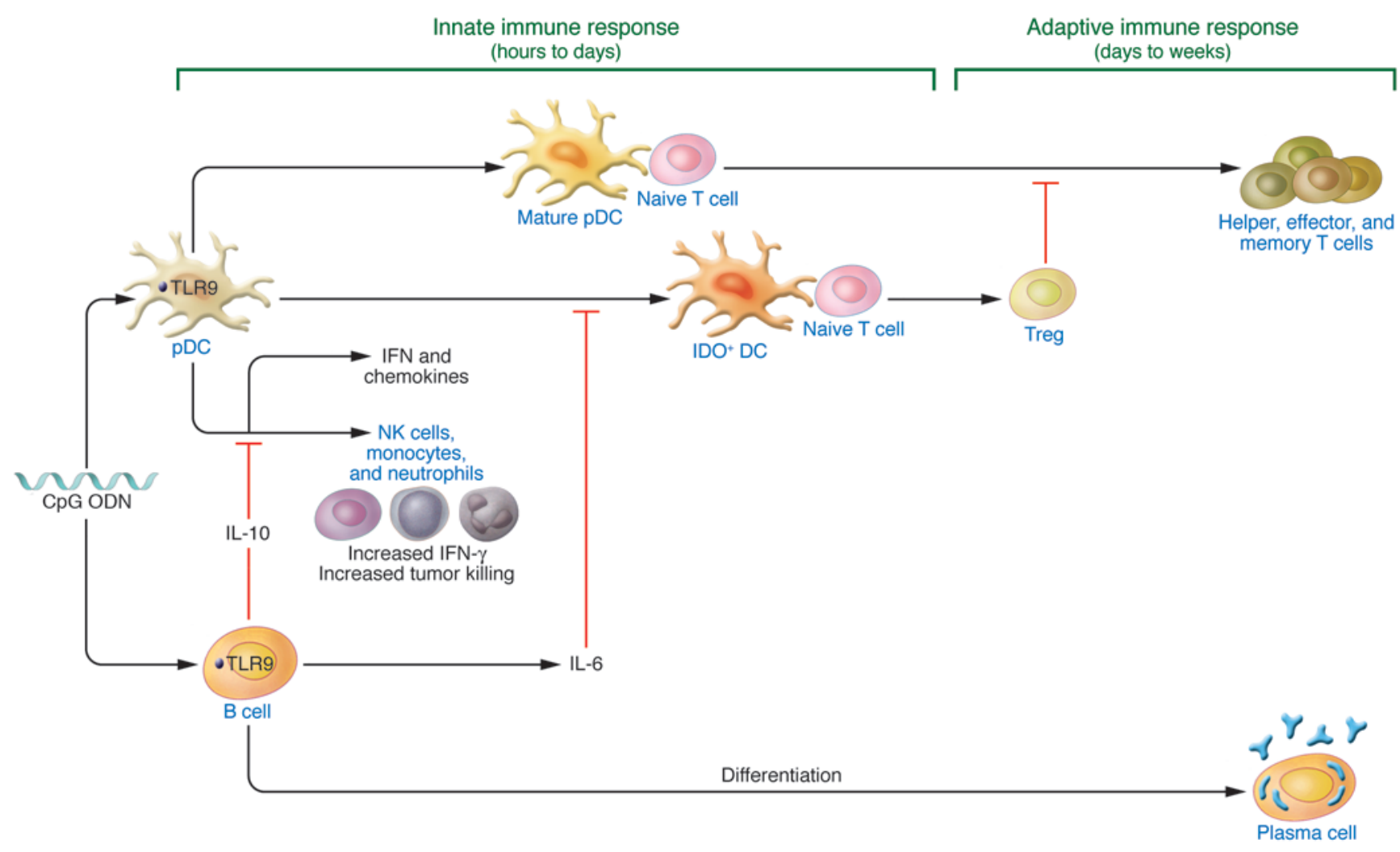

Figure 2

Activation of innate and adaptive immunity by TLR9 activation. Among human immune cells, only B cells and pDCs constitutively express TLR9. These cells endocytose DNA into an endosomal compartment where it binds to TLR9, forming a signaling complex. If the DNA contains unmethylated CpG motifs, TLR9 is stimulated, and the cell becomes activated. In pDCs, this results in type I IFN secretion, which activates NK cells, monocytes, and other APCs, and in the pDC maturation into a more effective APC able to activate naive T cells. Opposing these immuneboosting effects, pDCs activated through TLR9 also mediate immune-suppressive effects through counterregulatory factors such as indoleamine 2,3-dioxygenase $(35,36)$ and the generation of Tregs (29). In B cells, TLR9 stimulation results in the secretion of proinflammatory cytokines, such as IL-6, and in the release of immune regulatory cytokines that might limit the intensity of the inflammatory response, such as IL-10 (124). TLR9 activation of $B$ cells confers a greatly increased sensitivity to antigen stimulation and enhances their differentiation into antibody-secreting plasma cells. On balance, these immune effects of CpG DNA generally promote strong Th1 $\mathrm{CD} 4^{+}$and $\mathrm{CD} 8^{+} \mathrm{T}$ cell responses. However, the concurrent activation of counterregulatory pathways such as the induction of Tregs limit TLR9-induced immune activation, offering a potential for enhancing the therapeutic efficacy of TLR9 agonists by coadministration of antagonists of one or more of these inhibitory pathways.

tumor antigens (MUC1 peptide and GD3 ganglioside), CPG ODN induced the most Th1-biased immune responses with the highest levels of IFN- $\gamma$ secretion (40). Other vaccine adjuvant comparisons in mice also have demonstrated CPG ODN to be better at inducing antigen-specific Th1 responses than any other TLR agonist or unconjugated vaccine adjuvant, even including complete Freund's adjuvant (40-51). In comparisons of vaccine adjuvants in tumor-bearing mice, only CpG ODN induced antitumor responses that were strong enough to eliminate established tumors that had already grown to $5-10$ millimeters in diameter $(45,52)$. The mechanism of these vaccine-enhancing effects of CPG ODN includes both enhanced DC function leading to stronger $\mathrm{CD}^{+} \mathrm{T}$ cell responses and the generation of Th1 cytokines such as IFN- $\gamma$ and IL-12 (45-47, 49, 53). TLR9 activation might stimulate additional antitumor mechanisms beyond classical CTL: in one mouse tumor model, the addition of a CpG ODN to an adenoviral vector encoding a tumor antigen provided the expected survival benefit despite resulting in a substantial reduction in the vaccine-induced CTL response and the number of IFN- $\gamma$-secreting T cells (54). Therefore, CTL assays might provide an incomplete measure of TLR9-mediated antitumor effects.
Although CPG ODN are excellent adjuvants even in a simple saline solution with an antigen, their adjuvant activity can be further increased by the use of formulations that provide sustained release or by direct conjugation of the antigen and the ODN (reviewed in ref. 55). In contrast to the harsh local inflammatory effects of complete Freund's adjuvant, CpG ODN are relatively nonreactogenic. For these reasons, CPG ODN have arguably become the gold standard for vaccine adjuvants, with hundreds of publications showing them to be highly active and generally well tolerated with a wide variety of antigens, including peptides, proteins, live or killed viruses, DC vaccines, autologous cellular vaccines, and polysaccharide conjugates (55).

In humans, B-class CPG ODN have been used as adjuvants for infectious disease vaccination, either in combination with alum (56) or alone (57). In a phase I/II dose-escalation study, healthy subjects were randomized to receive three i.m. injections of an alum-absorbed HBV vaccine, Engerix-B, in saline or mixed with CPG 7909 at doses of $0.125,0.5$, or $1.0 \mathrm{mg}$ (56). HBV surface antigen-specific (HBsAg-specific) antibody responses were detected earlier and reached substantially higher titers in the CPG 7909 
Table 2

Published oncology clinical trials with TLR9 agonists

\begin{tabular}{|c|c|c|}
\hline Treatment & Tumor type & $\begin{array}{l}\text { Phase of clinical tri } \\
\text { (number of patient }\end{array}$ \\
\hline \multicolumn{3}{|l|}{ Vaccines } \\
\hline $\begin{array}{l}\text { CPG } 7909 \text { + MART1 } \\
\text { peptideA }^{\text {A }}\end{array}$ & Melanoma & Phase I (8) \\
\hline $\begin{array}{l}\text { CPG } 7909 \text { (dose of } 0.5 \\
\text { or } 1 \mathrm{mg} \text { ) + MAGE-3 } \\
\text { recombinant protein }\end{array}$ & Melanoma & Phase I (13) \\
\hline \multicolumn{3}{|l|}{ Monotherapy } \\
\hline \multirow[t]{4}{*}{ PF-3512676 ${ }^{A}$} & $\begin{array}{c}\text { NHL } \\
\text { Melanoma }\end{array}$ & $\begin{array}{l}\text { Phase I (23) } \\
\text { Phase II (20) }\end{array}$ \\
\hline & Melanoma & Phase I \\
\hline & $\begin{array}{c}\text { Cutaneous T cell lymphoma } \\
\text { BCC, melanoma }\end{array}$ & $\begin{array}{l}\text { Phase I/II (28) } \\
\text { Phase I (10) }\end{array}$ \\
\hline & Renal cell & Phase I (35) \\
\hline $\begin{array}{l}\text { CpG-28 (given } \\
\text { by intratumoral } \\
\text { administration) }\end{array}$ & Recurrent glioblastoma & Phase I (24) \\
\hline \multicolumn{3}{|l|}{ Combination therapies } \\
\hline 1018 ISS + Rituximab & NHL & Phase I (20) \\
\hline PF-3512676 \pm DTIC & Melanoma & Phase II (184) \\
\hline $\begin{array}{l}\text { Taxane/platin } \pm \\
\text { PF-3512676 }\end{array}$ & NSCLC (1st line) & Phase II (112) \\
\hline
\end{tabular}

Outcome

Reference

No objective responses,

66

but $\sim 10 \times$ increase in

antitumor $\mathrm{CD} 8{ }^{+} \mathrm{T}$ cells

2 PR among the 5 patients enrolled

in the $1 \mathrm{mg}$ CPG 7909 cohort; no responses

among the 8 in the $0.5 \mathrm{mg}$ cohort

Two late responses with no other treatment

2 PR (one ongoing at $2.5 \mathrm{yr}$ ) and $3 \mathrm{SD}$;

possible association with NK cell cytotoxicity

Peritumoral injection resulted in activation of $\mathrm{pDC}$ and $\mathrm{mDC}$ in SLN

$3 \mathrm{CR}$ and $6 \mathrm{PR}$

Local regression of $4 / 5 \mathrm{BCC}$ and $1 / 5$ melanoma (but with progression of distant metastases) 2 PR

2 minor responses, median survival

7.2 months; well tolerated

37

99

103

102

100

101

125

Induction of Th1 cytokines and chemokine secretion, good safety profile

Four PR in PF-3512676/DTIC-combination arm; 2 in DTIC-alone arm; no difference in survival Response rate doubled in chemotherapy + PF-3512676 combination arm compared with chemotherapy alone; 1 year survival improved to $50 \%$ from $33 \%$ in chemotherapy alone

ACPG 7909 and PF-3512676 are the same CpG ODN, but CPG 7909 refers to the compound when used as a vaccine adjuvant, and PF-3512676 refers to the compound when formulated without an adjuvant. BCC, basal cell carcinoma; CR, complete response; DTIC, dacarbazine; MAGE, melanoma antigenencoding gene; PR, partial response; SD, stable disease; SLN, sentinel lymph node.

recipients: a large proportion of the subjects randomized to receive CPG 7909 developed protective levels of HBsAg-specific IgG within two weeks of the priming vaccine dose compared with none of the subjects receiving the commercial vaccine Engerix-B in the absence of CPG 7909. The quality of the antibodies was also improved, with a substantial increase in avidity, suggesting an enhanced late affinity maturation process (58). The recipients of the two higher doses of CPG 7909 also showed a trend to more frequent positive CTL responses compared with controls. A different B-class CPG ODN, 1018 ISS, showed a generally similar adjuvant effect when mixed with HBsAg in the absence of alum, albeit at higher doses (57).

HBV vaccination with CPG 7909 rapidly induced protective antibody titers, even in HIV-infected subjects who had previously failed to attain protective antibody levels following treatment with a standard regimen of $\mathrm{HBV}$ vaccination, thereby demonstrating that TLR9 activation can overcome vaccine hyporesponsiveness (59). Moreover, these increased antibody titers persisted at protective levels for longer than three years after immunization. The HIV-infected subjects randomized to receive CPG 7909 with their HBV vaccinations also had substantially enhanced antigen-specific lymphocyte proliferation for at least two years compared with those receiving vaccine alone (59). In addition, coadministration of a $1 \mathrm{mg}$ dose of CPG 7909 with a one-tenth normal dose of an influenza vaccine in normal volunteers restored the full level of antigen-specific IFN- $\gamma$ secretion, further demonstrating the Th1enhancing effect of TLR9 activation (60).

\section{TLR9 agonists in cancer therapy}

TLR9 activation enhances tumor vaccination in humans. Antigen-specific $\mathrm{CD}^{+}$and $\mathrm{CD}^{+} \mathrm{T}$ cells can be induced by a tumor vaccine and can mediate immune rejection of solid tumors. Although tumor vaccines have shown outstanding results in mouse models, objective human clinical responses are rarely achieved (61). Therefore, the emphasis of many phase I and phase II clinical trials has shifted into detailed basic studies of the human $\mathrm{T}$ cell response to the tumor antigens during successful and unsuccessful vaccination. Ideally, both memory and effector $\mathrm{T}$ cells should be induced. However, there is an increasing appreciation of the fact that not all antitumor $\mathrm{T}$ cells are created equal - ineffective $\mathrm{T}$ cell triggering leads to much lower numbers of $\mathrm{T}$ cells that are less active killers and might even be tolerant of the tumor (62).

Melanoma-associated antigen recognized by $\mathrm{T}$ cells 1 (MART1) is a melanocyte protein that is expressed in most melanomas and also in several other types of tumors and has been used as a 


\section{Table 3}

Ongoing oncology clinical trials with TLR9 agonists

\begin{tabular}{|c|c|c|}
\hline Treatment & Tumor type & $\begin{array}{l}\text { Phase of clinical trial } \\
\text { (number of patients) }\end{array}$ \\
\hline \multicolumn{3}{|l|}{ Vaccines } \\
\hline $\begin{array}{l}\text { CPG } 7909 \text { + MAGE-3.A1 peptide } \\
\text { CPG } 7909 \text { + MART1 natural and analog peptides + tyrosinase peptide + Montanide ISA-51 } \\
\text { CPG } 7909 \text { + cyclophosphamide + fludarabine + autologous PBMCs + MART1 in IFA } \\
\text { CPG } 7909 \text { (within the adjuvant AS15) + MAGE-3 His fusion protein } \\
\text { CPG } 7909 \text { (within the adjuvant AS15) + HER2 recombinant protein }\end{array}$ & $\begin{array}{l}\text { Melanoma } \\
\text { Melanoma } \\
\text { Melanoma } \\
\text { Melanoma } \\
\text { Breast }\end{array}$ & $\begin{array}{c}\text { Phase I/II (14)A } \\
\text { Phase I (27)A } \\
\text { Phase I (12)A } \\
\text { Phase II (68) } \\
\text { Phase I/II (at least } 40)^{A}\end{array}$ \\
\hline \multicolumn{3}{|l|}{ Monotherapy } \\
\hline $\begin{array}{l}\text { PF-3512676 } \\
\text { IM0-2055 }\end{array}$ & $\begin{array}{l}\text { CLL (2nd line) } \\
\text { Renal cell (1st and 2nd line) }\end{array}$ & $\begin{array}{l}\text { Phase I }(48)^{A} \\
\text { Phase I }(92)^{B}\end{array}$ \\
\hline \multicolumn{3}{|l|}{ Combination therapies } \\
\hline $\begin{array}{l}1018 \text { ISS + rituximab } \\
\text { PF-3512676 + local radiation } \\
\text { Paclitaxel/carboplatin } \pm \text { PF- } 3512676 \\
\text { Gemcitabine/cisplatin } \pm \text { PF- } 3512676 \\
\text { Paclitaxel/carboplatin/bevacizumab } \pm \text { PF-3512676 } \\
\text { Erlotinib } \pm \text { PF-3512676 } \\
\text { Pemetrexed } \pm \text { PF-3512676 } \\
\text { PF-3512676 + KLH (to assess immune reconstitution after transplant) }\end{array}$ & $\begin{array}{l}\text { NHL (2nd line) } \\
\text { NHL } \\
\text { NSCLC (1st line) } \\
\text { NSCLC (1st line) } \\
\text { NSCLC (1st line) } \\
\text { NSCLC (2nd line) } \\
\text { NSCLC (2nd line) } \\
\text { Leukemia/lymphoma following }\end{array}$ & $\begin{array}{l}\text { Phase II }(30)^{A} \\
\text { Phase I/II }(30)^{A} \\
\text { Phase III }(800)^{A} \\
\text { Phase III }(800)^{A} \\
\text { Phase II }(140)^{A} \\
\text { Phase II }(130)^{A} \\
\text { Phase II }(130)^{A} \\
\text { Phase I }(25)^{A}\end{array}$ \\
\hline $\begin{array}{l}1018 \text { ISS + irinotecan + cetuximab } \\
\text { IM0-2055 + gemcitabine + carboplatin }\end{array}$ & $\begin{array}{l}\text { Colorectal (2nd line) } \\
\text { Refractory solid tumors }\end{array}$ & $\begin{array}{c}\text { Phase I (15) } \\
\text { Phase I/II } \\
\text { (dose escalation) }{ }^{\mathrm{A}}\end{array}$ \\
\hline
\end{tabular}

AFurther information about these clinical trials can be found at www.clinicaltrials.gov. BFurther information about this clinical trial can be found at www. iderapharma.com/drug_development.php. CLL, chronic lymphocytic leukemia; IMO, immune modulatory oligonucleotide.

component of some investigational melanoma vaccines. MART1 is unique among tumor antigens in that both normal subjects and patients with melanoma have a remarkably high frequency of $\mathrm{T}$ cells specific for this antigen. Many of these $\mathrm{T}$ cells are specific for one particular region of the protein that can be synthesized as a peptide for more detailed studies by flow cytometry using tetramers and other analytic techniques, enabling detailed investigations of the quantity and quality of the $\mathrm{T}$ cell response during vaccination with different adjuvants or formulations $(63,64)$. These studies have revealed that there is no increase in the frequency of $T$ cells specific for this MART1 peptide following vaccination with a synthetic form of this peptide if the peptide is formulated in saline or mixed with the saponin QS-21 and the TLR4 ligand monophosphoryl lipid A, which has been used as a vaccine adjuvant in other settings. In contrast, vaccination with the MART1-derived peptide in incomplete Freund's adjuvant (IFA) stimulated about half of vaccinated patients to generate increased frequencies of MART1-specific CD8 $8^{+} \mathrm{T}$ cells in the blood, up to an average frequency of $0.1 \%-0.2 \%$ (65). This adjuvant effect of IFA was markedly enhanced upon combination with the TLR9 agonist CPG 7909 at a low dose of $0.5 \mathrm{mg}$ : all vaccinated melanoma patients responded with increased frequencies of antigen-specific $\mathrm{CD}^{+} \mathrm{T}$ cells, which reached a mean frequency of more than $1 \%$ (66) (Table 2). This roughly 10-fold increase in antigen-specific $\mathrm{T}$ cell frequency makes this IFA and TLR9 agonist combination the strongest reported stimulator of human $\mathrm{CD}^{+} \mathrm{T}$ cell responses in the blood (66). Most importantly, ex vivo analyses of these tumor-specific $\mathrm{T}$ cells demonstrated that they had differentiated to effector cells (67). Unfortunately, the MART1-specific tumor- infiltrating lymphocytes in the patients had a less differentiated phenotype than those in the blood, with lower expression of the cytotoxic effectors perforin and granzymes and lower inducible expression of IFN- $\gamma$, indicating that measurement of antitumor responses in the blood does not give the complete picture and suggesting that further optimization of this approach to vaccination will be needed if it is to reach its full clinical potential (67). All patients developed inflammatory injection site reactions, which peaked about two weeks after vaccination; several patients also showed reactivation of local inflammation at earlier vaccination sites. Transient mild systemic flu-like side effects from the vaccination were common and included myalgias, arthalgias, fatigue, nausea, malaise, and headache (66). Vaccination of these patients was not associated with dramatic clinical responses, and tumors in the patients contained high numbers of Tregs (67), suggesting that the clinical efficacy of this approach might be enhanced by Treg depletion or inactivation or perhaps by the incorporation of a greater variety of tumor antigens in the vaccine, a higher dose of CPG 7909, or other changes to the clinical protocol.

Although the use of peptide antigens allows the most precise analysis of the immune response to tumor vaccination, a whole recombinant protein has the potential advantage of including a greater variety of tumor epitopes. A clinical trial has been conducted in advanced melanoma patients using a recombinant melanoma antigen-encoding gene 3 (MAGE-3) protein and comparing two doses of CPG 7909; a low, vaccine-adjuvant dose of $0.5 \mathrm{mg}$ (the first eight patients were enrolled at this dose) and a high vaccineadjuvant dose of $1 \mathrm{mg}$ (five patients were enrolled in this cohort). There were no clinical responses in the first cohort, but two of the 


\section{Table 4}

Nonvaccine therapeutic approaches that enhance TLR9-mediated antitumor activity in mice

\begin{tabular}{|c|c|c|}
\hline Approach & Therapy & Reference \\
\hline \multirow[t]{11}{*}{ Immunotherapy } & Tumor-specific antibody & 72 \\
\hline & CD40-specific antibody & 73 \\
\hline & IL-10-specific antibody & 74 \\
\hline & IL-10-specific antibody + CCL16 & 75 \\
\hline & $\begin{array}{l}\text { IL-10-specific antibody } \\
\text { + Treg depletion }\end{array}$ & 76 \\
\hline & FLT3 ligand \pm vaccine & 79,80 \\
\hline & IL-13 exotoxin fusion protein & 81 \\
\hline & IL-18 & 82 \\
\hline & CTLA4-specific antibody + vaccine & 77,78 \\
\hline & TLR3 agonist & 83 \\
\hline & TLR5 agonist & 84 \\
\hline Antiangiogenesis & EGFR-specific antibody \pm irinotecan & 85 \\
\hline \multirow{4}{*}{$\begin{array}{l}\text { Physical disruption } \\
\text { of the tumor }\end{array}$} & Radiotherapy & 86 \\
\hline & Cryoablation & 89 \\
\hline & Surgical resection & 87 \\
\hline & $\begin{array}{l}\text { Surgical resection and whole } \\
\text { tumor vaccine and GM-CSF }\end{array}$ & 88 \\
\hline \multirow[t]{6}{*}{ Chemotherapy } & Cyclophosphamide & 87,90 \\
\hline & Topotecan & 87,91 \\
\hline & 5-Fluorouracil & 92 \\
\hline & Gemcitabine & 93,94 \\
\hline & Alimta & 94 \\
\hline & Coramsine & 95 \\
\hline
\end{tabular}

CCL16, CC chemokine ligand 16; CTLA4, CTL-associated antigen 4; FLT3, FMS-related tyrosine kinase 3 .

five patients receiving the higher dose of CPG 7909 had partial responses that became apparent after at least seven vaccinations (68). The clinical utility of TLR9 agonists currently is being investigated in a number of additional vaccine trials that are underway, with results expected during the coming years (Table 3).

TLR9 agonist monotherapy can promote antigen-specific antitumor immunity without a vaccine. In mice with relatively small tumors, up to a few millimeters in diameter, CPG monotherapy can be sufficient to induce $\mathrm{T}$ cell-mediated tumor regression $(69,70)$. In most, but not all, mouse tumor models, the efficacy of $\mathrm{CPG}$ monotherapy requires injection of the ODN into the tumor (reviewed in ref. 71). To induce rejection of larger or poorly immunogenic tumors, the CPG ODN generally needs to be combined with either a tumor vaccine (reviewed in ref. 71) or with other effective antitumor strategies, such as monoclonal antibody therapy (72-78), other immune therapies (including in combination with ligands for TLR3 or TLR5) (79-84), angiogenesis inhibitors (85), radiation therapy (86), surgery $(87,88)$, cryotherapy (89), and chemotherapy (87, 90-95) (Table 4). In humans also, monotherapy with the TLR9 agonist CPG 7909 (now called PF-3512676 when used in oncology without a vaccine) or another B-class CPG ODN, 1018 ISS, activates NK cells and induces a Th1 cytokine response in humans with B cell lymphomas $(37,96)$. Of $23 \mathrm{NHL}$ patients in the i.v. dose-escalation study of PF-3512676, there were two late clinical responses, which suggests a potential role for this approach as one part of a combination treatment regimen (37). Although CPG ODN are strong mitogens for normal B cells, there was no apparent exacerbation of the lymphoma in these patients, perhaps due to the increased immunogenicity of the tumor cells or the preferential induction of apoptosis in tumor cells stimulated through TLR9 $(97,98)$. Objective responses have been seen in some subjects receiving PF-3512676 monotherapy for the treatment of melanoma, basal cell carcinoma, renal cell cancer, or cutaneous $\mathrm{T}$ cell lymphoma (Table 2) (99-102). In the melanoma patients, both intratumoral and s.c. PF-3512676 monotherapy activate pDCs and myeloid DCs (because myeloid DCs do not express TLR9, their activation is indirect) $(99,103)$. And in a dose-escalation study, one of five melanoma patients receiving intratumoral PF-3512676 showed complete regression of the injected lesion but progressive disease at distant sites; four of five patients with basal cell carcinoma treated in this manner experienced regressions (100). These results with intratumoral PF-3512676 seem generally comparable to the partial activity seen with imiquimod, a TLR7 agonist that has been used topically in the treatment of several premalignant and malignant skin diseases (5). In contrast, when given by systemic injection, imiquimod showed no antitumor activity in clinical trials despite some positive results in mouse models (104). Objective clinical responses occurred in 2 out of 20 advanced melanoma patients receiving s.c. PF-3512676 at a dose of $6 \mathrm{mg}$ weekly and might be associated with increased NK cell cytotoxicity (99). Of 35 patients with advanced renal cell carcinoma who were enrolled in a dose-escalation trial of PF-3512676, two had confirmed objective responses (101), further demonstrating the ability of this investigational agent to provide some antitumor activity. Twenty-eight patients with advanced cutaneous $\mathrm{T}$ cell lymphoma who had failed an average of six prior therapies were enrolled in a dose-escalation study of PF-3512676 in which they were treated with weekly s.c. administration of the agent in sequential cohorts starting at $0.08 \mathrm{mg} / \mathrm{kg}$ and escalating to $0.36 \mathrm{mg} / \mathrm{kg}$ (102). There were three complete and six partial responses and little toxicity beyond injection site reactions and flu-like symptoms. Responses were evident starting as early as two weeks, occurred in all of the dose groups except for the lowest, and persisted for the duration of the study. Together, these clinical trials of TLR9 therapy as a single agent are encouraging for a good safety profile, but the frequency of objective responses has been relatively low, and the focus of ongoing clinical trials therefore has shifted to combination therapies in an attempt to increase the clinical effectiveness of administering TLR9 agonists.

Chemotherapy can enhance the antitumor effects of immune stimulators, including TLR9 activation. Since chemotherapies are commonly considered to be immunosuppressive, it might seem counterintuitive to combine such a therapy with an immune therapy. Nevertheless, numerous studies in rodents have demonstrated that many different chemotherapy regimens can enhance various immune therapies. For example, both cyclophosphamide and paclitaxel enhance the Th1 response to a tumor vaccine when given prior to vaccination (but not if given following vaccination) $(105,106)$, and gemcitabine increases the $\mathrm{CD} 8^{+} \mathrm{T}$ cell response when given prior to an immune-activating CD40-specific antibody (107). Further studies have elucidated several potential mechanisms for this somewhat paradoxical synergy. First, cyclophosphamide and methotrexate reduce the number and/or function of Tregs in mice and rats, improving the activity of tumor vaccines (108-110). The results of these and other studies suggest that Tregs might be more sensitive to certain chemotherapy regimens than normal $\mathrm{T}$ cells, providing a rationale for following chemotherapy with an immunotherapy (111-113). Second, docetaxel therapy in mice promotes the survival of activated T cells to a GM-CSF-producing tumor vaccine (114), 


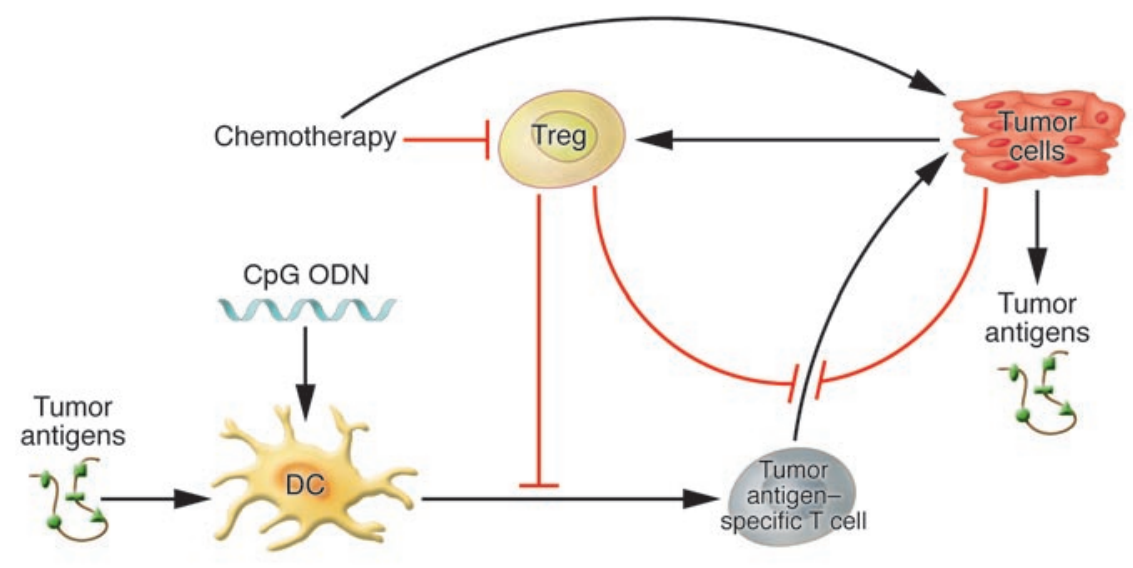

Figure 3

Potential mechanism to explain the observed antitumor synergy of TLR9 with chemotherapy. Tumor antigens are constitutively present in cancer patients and are taken up by DCs in the tumor and secondary lymphoid organs. In patients with established tumors, the immune system fails to respond to the tumor antigens due to the tumor-induced Tregs and other immunesuppressive effects. Certain chemotherapy regimens effectively deplete Tregs and also disrupt the tumor, releasing additional antigen and interfering with the ability of the tumor and its mesenchymal support structures to suppress the immune system. When such chemotherapy is followed by treatment with a TLR9 agonist (CpG ODN), DCs bearing tumor antigens are stimulated to mature and become effective inducers of a CTL response, which in the postchemotherapy environment is now better able to attack the tumor, leading to improved survival. of immunotherapy, the focus of many investigators has shifted to the immune effects of chemotherapy and their possible applications in improving the outcomes of combination therapy in humans.

The efficacy of TLR9 agonists is increased by Treg depletion. Recent studies in mouse models of cancer show that for at least some tumor vaccines (without TLR9 agonists), the deletion or inhibition of Tregs is essential for the recruitment to the antitumor response of the highest avidity $\mathrm{CD}^{+} \mathrm{T}$ cells, which are the most potent tumor killers $(110,119)$. Chemotherapies reported to deplete Treg numbers and/or function in mice include cyclophosphamide, methotrexate, and fludaribine $(90,108-110)$ as well as docetaxel, which induces a mild lymphodepletion with the loss of both Tregs and memory $\mathrm{T}$ cells but is associated with substantially prolonged survival of activated $\mathrm{T}$ cells (114). Doxorubicin might augment immunotherapy through a different mechanism than docetaxel or other taxanes and other chemotherapies since it alone does not increase the number of providing a possible hint that the antitumor $\mathrm{T}$ cells activated by an immunotherapy might have a greater resistance to the toxic effects of taxane chemotherapy compared with naive $\mathrm{T}$ cells (or Tregs). Third, etoposide and mitomycin $C$ have recently been reported to cause calreticulin to be exposed on the surface of apoptotic tumor cells, conferring on them immunogenicity to an immune therapy (115). Finally, a tumor antigen-pulsed DC vaccine has been shown to decrease the toxicity of the combination therapy of 5-fluorouracil and irinotecan in a model of colon cancer (116).

Evidence of the immune-boosting effects of chemotherapy has also come from human clinical trials. First, humans receiving certain chemotherapy regimens, such as taxanes, actually show increases in some T cell and NK cell functions (111-113). Second, cyclophosphamide and fludarabine have been proposed to function by "making space"; chemotherapy-induced lymphodepletion followed by homeostatic proliferation of transferred autologous $\mathrm{T}$ cells has induced several impressive clinical responses to therapy with a combination of adoptive transfer of activated antitumor T cells and IL-2 (117). Third, gemcitabine, oxaliplatin, and 5 -fluorouracil result in reduced numbers of Tregs and increased numbers of tumor-specific CTLs when used in combination with GM-CSF and IL-2 (118).

The mechanisms through which different chemotherapy regimens enhance immunotherapy are likely to be diverse and cannot be accounted for solely by tumor debulking, since in one study, there was no survival benefit from immunotherapy in mice whose tumors were surgically resected to the same residual tumor volume reached in the gemcitabine-treated mice (107). Furthermore, even when tumor challenge was delayed until one week after the last dose of chemotherapy to avoid the cytolytic effect on the tumor cells, it still enhanced the protective effect of tumor vaccination in mice (105). Since the direct antitumor effects of chemotherapy generally are insufficient to account for its enhancement tumor-specific T cells, does not seem to eliminate Treg activity, and enhances vaccination only when given at the time of $\mathrm{T}$ cell expansion, not if used as a pretreatment $(105,110)$. In recent human clinical trials, gemcitabine, oxaliplatin, and fluorouracil also have been reported to reduce Treg numbers, suggesting possible utility for regimens containing these agents in enhancing immunotherapy $(118,120)$.

In mouse tumor models, TLR9 activation has been reported to synergize with a wide range of chemotherapy regimens, including cyclophosphamide $(87,90)$, topotecan $(87,91)$, 5-fluorouracil (92), gemcitabine $(93,94)$, alimta (94), and coramsine (95). The mechanism of this synergy may result at least in part from the effects of these chemotherapies in reducing Treg numbers. Established tumors are associated with increased Treg activity, which protects the tumor from immune rejection and is not readily overcome by TLR9 activation alone. Treg-depleting chemotherapies not only directly disrupt the tumor and induce tumor cell apoptosis and immunogenicity but also eliminate Treg function, making the tumor far more susceptible to TLR9induced innate and adaptive immune responses. In effect, in the altered immune environment that follows chemotherapy, TLR9 activation of pDCs might be sufficient to boost effective Th1 responses against tumor antigens that had previously been ignored by the immune system (Figure 3 ). Indeed, in mouse models of rhabdomyosarcoma treated with cyclophosphamide (87), we have found that the prolonged survival of mice receiving chemotherapy combined with s.c. PF-3512676 is mediated by an enhanced antitumor $\mathrm{T}$ cell response.

Clinical development of chemotherapy combined with TLR9 agonist. Based on these results, we conducted a phase II randomized controlled human clinical trial to investigate the effect of adding PF-3512676 to standard taxane and platinum chemotherapy in previously untreated stage IIIb or stage IV non-small cell lung 
carcinoma (NSCLC) (121). A total of 111 patients were randomized to receive four to six 3-week cycles of standard chemotherapy alone or in combination with $0.2 \mathrm{mg} / \mathrm{kg}$ s.c. PF-3512676 on the first day of weeks two and three of each cycle. The primary endpoint for the trial, objective response rate, was higher in the patients who received standard chemotherapy plus PF-3512676 than in those who received standard chemotherapy alone (38\% versus $19 \%$ for confirmed and unconfirmed responses; $P=0.048)(121)$. There was also a trend to improvement in oneyear survival from $33 \%$ in the patients randomized to receive standard chemotherapy to $50 \%$ in the patients receiving the combination (121). The most common side effects were mild to moderate injection site reactions and transient flu-like symptoms. Grade 3 or 4 neutropenia was more common in the combination arm and is thought to reflect neutrophil redistribution, as febrile neutropenia and grade 3 or 4 infections were less common in the combination arm than in the chemotherapy alone arm. Thrombocytopenia, which is a known sequence-independent effect of PS ODN and which has been observed in all systemic clinical trials of antisense PS ODN in applications such as infectious disease and oncology (122), was seen more commonly in patients receiving the combination but with no apparent increase in bleeding events. To pursue these encouraging results, 2 phase III human clinical trials of PF-3512676 combined with standard platinumbased doublet chemotherapy (one trial using the doublet of cisplatin and gemcitabine and the other trial using the doublet of carboplatin and paclitaxel) have been initiated in advanced NSCLC, and several phase II trials have begun exploring other combination regimens with PF-3512676 (Table 3).

It seems probable that not all chemotherapy regimens will be equally effective when combined with TLR9 activation. Dacarbazine, a relatively weak chemotherapy that has not been shown to deplete Tregs or to boost any other immunotherapy, resulted in no improvement in survival and only a slight increase in response rate when administered in combination with CPG 7909 in a random- ized phase II clinical trial performed in 184 advanced melanoma patients (123). Further studies into the effects of various chemotherapy regimens on immune function might make it possible to design combination therapies that will predictably provide greater clinical benefit to patients.

\section{Conclusions}

The studies performed to date show great promise for the clinical application of TLR9 activation with CPG ODN for enhancing the clinical outcomes from cancer vaccination, conventional chemotherapy, and other therapeutic modalities. The safety of this approach has been quite good: a human maximal tolerated dose has yet to be identified, no clinically meaningful increase in chemotherapy-related toxicity has been reported for the addition of TLR9 activation, and there have been no definite reports to date of induction of systemic autoimmune disease from treatment of several thousand humans with TLR9 agonists. Human clinical trials with $\mathrm{CPG} O \mathrm{ODN}$ as vaccine adjuvants confirm that they provide a marked acceleration and amplification of both $\mathrm{CD}^{+} \mathrm{T}$ cell responses and $\mathrm{B}$ cell responses. Nevertheless, tumors have multiple means of suppressing or evading vaccineinduced antitumor immunity, and it remains unclear to what extent TLR9 activation will be able to overcome these defenses and improve survival. Most probably, it will be necessary to use combinations of synergistic therapies to achieve the full clinical potential of this approach.

\section{Acknowledgments}

The author thanks Meredith Larade for expert assistance with manuscript preparation.

Address correspondence to: Arthur M. Krieg, Coley Pharmaceutical Group, 93 Worcester Street, Suite 101, Wellesley, Massachusetts 02481, USA. Phone: (781) 431-9084; Fax: (781) 431-0951; E-mail: akrieg@coleypharma.com.
1. Creagh, E.M., and O'Neill, L.A. 2006. TLRs, NLRs and RLRs: a trinity of pathogen sensors that co-operate in innate immunity. Trends Immunol. 27:352-357.

2. Iwasaki, A., and Medzhitov, R. 2004. Toll-like receptor control of the adaptive immune responses. Nat. Immunol. 5:987-995

3. Takeda, K., Kaisho, T., and Akira, S. 2003. Toll-like receptors. Annu. Rev. Immunol. 21:335-376.

4. Baldridge, J.R., et al. 2004. Taking a Toll on human disease: Toll-like receptor 4 agonists as vaccine adjuvants and monotherapeutic agents. Expert Opin. Biol. Ther. 4:1129-1138.

5. Burns, C.A., and Brown, M.D. 2005. Imiquimod for the treatment of skin cancer. Dermatol. Clin. 23:151-64, vii.

6. Hemmi, H., et al. 2000. A Toll-like receptor recognizes bacterial DNA. Nature. 408:740-745.

7. Liu, Y.J. 2005. IPC: professional type 1 interferonproducing cells and plasmacytoid dendritic cell precursors. Annu. Rev. Immunol. 23:275-306.

8. Hemmi, H., Kaisho, T., Takeda, K., and Akira, S. 2003. The roles of Toll-like receptor 9, MyD88, and DNA-dependent protein kinase catalytic subunit in the effects of two distinct CpG DNAs on dendritic cell subsets. J. Immunol. 170:3059-3064.

9. Vollmer,J., et al. 2004. Oligodeoxynucleotides lacking CpG dinucleotides mediate Toll-like receptor 9 dependent $\mathrm{T}$ helper type 2 biased immune stimulation. Immunology. 113:212-223.

10. Ishii, K.J., et al. 2006. A Toll-like receptor-indepen- dent antiviral response induced by double-stranded B-form DNA. Nat. Immunol. 7:40-48.

11. Okabe, Y., Kawane, K., Akira, S., Taniguchi, T., and Nagata, S. 2005. Toll-like receptor-independent gene induction program activated by mammalian DNA escaped from apoptotic DNA degradation. J. Exp. Med. 202:1333-1339.

12. Stetson, D.B., and Medzhitov, R. 2006. Recognition of cytosolic DNA activates an IRF3-dependent innate immune response. Immunity. 24:93-103.

13. Spies, B., et al. 2003. Vaccination with plasmid DNA activates dendritic cells via Toll-like receptor 9 (TLR9) but functions in TLR9-deficient mice. J. Immunol. 171:5908-5912.

14. Krieg, A.M. 2006. Therapeutic potential of Tolllike receptor 9 activation. Nat. Rev. Drug Discov. 5:471-484.

15. Ishii, K.J., et al. 2002. Potential role of phosphatidylinositol 3 kinase, rather than DNA-dependent protein kinase, in CpG DNA-induced immune activation. J. Exp. Med. 196:269-274.

16. Latz, E., et al. 2004. TLR9 signals after translocating from the ER to CpG DNA in the lysosome. Nat. Immunol. 5:190-198.

17. Rutz, M., et al. 2004. Toll-like receptor 9 binds single-stranded CPG-DNA in a sequence- and $\mathrm{pH}$ dependent manner. Eur. J. Immunol. 34:2541-2550.

18. Ishii, K.J., and Akira, S. 2006. Innate immune recognition of, and regulation by, DNA. Trends Immunol. 27:525-532.

19. Schlecht, G., et al. 2004. Murine plasmacytoid dendritic cells induce effector/memory CD8+ $\mathrm{T}$-cell responses in vivo after viral stimulation. Blood. 104:1808-1815.

20. Asselin-Paturel, C., et al. 2001. Mouse type I IFNproducing cells are immature APCs with plasmacytoid morphology. Nat. Immunol. 2:1144-1150.

21. Fonteneau, J.F., et al. 2003. Activation of influenza virus-specific CD4+ and CD8+ T cells: a new role for plasmacytoid dendritic cells in adaptive immunity. Blood. 101:3520-3526.

22. Boonstra, A., et al. 2003. Flexibility of mouse classical and plasmacytoid-derived dendritic cells in directing $T$ helper type 1 and 2 cell development: dependency on antigen dose and differential tolllike receptor ligation. J. Exp. Med. 197:101-109.

23. Krug, A., et al. 2003. Interferon-producing cells fail to induce proliferation of naive $T$ cells but can promote expansion and $\mathrm{T}$ helper 1 differentiation of antigen-experienced unpolarized T cells. J. Exp. Med. 197:899-906.

24. Rothenfusser, S., et al. 2004. CpG-A and CpG-B oligonucleotides differentially enhance human peptide-specific primary and memory CD8+ T-cell responses in vitro. Blood. 103:2162-2169.

25. Zou, W. 2006. Regulatory T cells, tumour immunity and immunotherapy. Nat. Rev. Immunol. 6:295-307.

26. Pasare, C., and Medzhitov, R. 2003. Toll pathway-dependent blockade of CD4+CD25+ T cellmediated suppression by dendritic cells. Science. 299:1033-1036. 
27. Kubo, T., et al. 2004. Regulatory T cell suppression and anergy are differentially regulated by proinflammatory cytokines produced by TLR-activated dendritic cells. J. Immunol. 173:7249-7258.

28. Sutmuller, R.P., et al. 2006. Toll-like receptor 2 controls expansion and function of regulatory T cells. J. Clin. Invest. 116:485-494. doi:10.1172/JCI25439.

29. Moseman, E.A., et al. 2004. Human plasmacytoid dendritic cells activated by $\mathrm{CPG}$ oligodeoxynucleotides induce the generation of CD4+CD25+ regulatory T cells. J. Immunol. 173:4433-4442.

30. Veldhoen, M., Hocking, R.J., Atkins, C.J., Locksley, R.M., and Stockinger, B. 2006. TGFbeta in the context of an inflammatory cytokine milieu supports de novo differentiation of IL-17-producing T cells. Immunity. 24:179-189.

31. Sharma, S., Dominguez, A.L., and Lustgarten, J. 2006. High accumulation of T regulatory cells prevents the activation of immune responses in aged animals. J. Immunol. 177:8348-8355.

32. Oldenhove, G., et al. 2003. CD4+CD25+ regulatory T cells control $\mathrm{T}$ helper cell type 1 responses to foreign antigens induced by mature dendritic cells in vivo J. Exp. Med. 198:259-266.

33. Toka, F.N., Suvas, S., and Rouse, B.T. 2004. CD4+ $\mathrm{CD} 25+\mathrm{T}$ cells regulate vaccine-generated primary and memory CD8 + T-cell responses against herpes simplex virus type 1. J. Virol. 78:13082-13089.

34. Ghoreishi, M., and Dutz, J.P. 2006. Tolerance induction by transcutaneous immunization through ultraviolet-irradiated skin is transferable through $\mathrm{CD} 4+\mathrm{CD} 25+\mathrm{T}$ regulatory cells and is dependent on host-derived IL-10. J. Immunol. 176:2635-2644.

35. Wingender, G., et al. 2006. Systemic application of CPG-rich DNA suppresses adaptive T cell immunity via induction of IDO. Eur. J. Immunol. 36:12-20.

36. Mellor, A.L., et al. 2005. Cutting edge: CpG oligonucleotides induce splenic CD19+ dendritic cells to acquire potent indoleamine 2,3-dioxygenasedependent $T$ cell regulatory functions via IFN Type 1 signaling. J. Immunol. 175:5601-5605.

37. Link, B., et al. 2006. Oligodeoxynucleotide CPG 7909 delivered as intravenous infusion demonstrates immunologic modulation in patients with previously treated non-Hodgkin's lymphoma. J. Immunother. 29:558-568.

38. Emens, L.A., Reilly, R.T., and Jaffee, E.M. 2004. Augmenting the potency of breast cancer vaccines: combined modality immunotherapy. Breast Dis. 20:13-24.

39. Pulendran, B. 2005. Variegation of the immune response with dendritic cells and pathogen recognition receptors. J. Immunol. 174:2457-2465.

40. Kim, S.K., et al. 2000. Comparison of the effect of different immunological adjuvants on the antibody and T-cell response to immunization with MUC1$\mathrm{KLH}$ and GD3-KLH conjugate cancer vaccines. Vaccine. 18:597-603.

41. Chu, R.S., Targoni, O.S., Krieg, A.M., Lehmann, P.V., and Harding, C.V. 1997. CpG oligodeoxynucleotides act as adjuvants that switch on T helper 1 (Th1) immunity. J. Exp. Med. 186:1623-1631.

42. Lipford, G.B., et al. 1997. CpG-containing synthetic oligonucleotides promote $\mathrm{B}$ and cytotoxic $\mathrm{T}$ cell responses to protein antigen: a new class of vaccine adjuvants. Eur. J. Immunol. 27:2340-2344.

43. Roman, M., et al. 1997. Immunostimulatory DNA sequences function as Thelper-1-promoting adjuvants. Nat. Med. 3:849-854.

44. Schwarz, K., et al. 2003. Role of Toll-like receptors in costimulating cytotoxic T cell responses. Eur. J. Immunol. 33:1465-1470.

45. Zwaveling, S., et al. 2002. Established human papillomavirus type 16-expressing tumors are effectively eradicated following vaccination with long peptides. J. Immunol. 169:350-358.

46. Stern, B.V., Boehm, B.O., and Tary-Lehmann, M. 2002. Vaccination with tumor peptide in $\mathrm{CPG}$ adjuvant protects via IFN-gamma- dependent CD4 cell immunity. J. Immunol. 168:6099-6105.

47. Miconnet, I., et al. 2002. CpG are efficient adjuvants for specific CTL induction against tumor antigenderived peptide. J. Immunol. 168:1212-1218.

48. Kim, T.Y., et al. 2002. Both E7 and CPG-oligodeoxynucleotide are required for protective immunity against challenge with human papillomavirus 16 (E6/E7) immortalized tumor cells: involvement of CD4+ and CD8+ T cells in protection. Cancer Res. 62:7234-7240.

49. Davila, E., and Celis, E. 2000. Repeated administration of cytosine-phosphorothiolated guanine- containing oligonucleotides together with peptide/protein immunization results in enhanced CTL responses with anti-tumor activity. J. Immunol. 165:539-547.

50. Warren, T.L., et al. 2000. APC stimulated by CpG oligodeoxynucleotide enhance activation of MHC class I-restricted T cells. J. Immunol. 165:6244-6251.

51. Weeratna, R.D., McCluskie, M.J., Xu, Y., and Davis, H.L. 2000. CPG DNA induces stronger immune responses with less toxicity than other adjuvants. Vaccine. 18:1755-1762.

52. Heckelsmiller, K., et al. 2002. Combined dendritic cell- and $\mathrm{CPG}$ oligonucleotide-based immune therapy cures large murine tumors that resist chemotherapy. Eur. J. Immunol. 32:3235-3245.

53. Sandler, A.D., et al. 2003. CPG oligonucleotides enhance the tumor antigen-specific immune response of a granulocyte macrophage colonystimulating factor-based vaccine strategy in neuroblastoma. Cancer Res. 63:394-399.

54. Lubaroff, D.M., et al. 2006. Decreased cytotoxic T cell activity generated by co-administration of PSA vaccine and $\mathrm{CPG} O \mathrm{ODN}$ is associated with increased tumor protection in a mouse model of prostate cancer. Vaccine. 24:6155-6162.

55. McCluskie, M.J., and Krieg, A.M. 2006. Enhancement of infectious disease vaccines through TLR9dependent recognition of CPG DNA. In From innate immunity to immunological memory. B. Pulendran and R. Ahmed, editors. Springer. New York, New York, USA. 155-178.

56. Cooper, C.L., et al. 2004. CPG 7909, an immunostimulatory TLR9 agonist oligodeoxynucleotide, as adjuvant to Engerix-B HBV vaccine in healthy adults: a double-blind Phase I/II study. J. Clin. Immunol. 24:693-702.

57. Halperin, S.A., et al. 2003. A phase I study of the safety and immunogenicity of recombinant hepatitis B surface antigen co-administered with an immunostimulatory phosphorothioate oligonucleotide adjuvant. Vaccine. 21:2461-2467.

58. Siegrist, C.A., et al. 2004. Co-administration of $\mathrm{CPG}$ oligonucleotides enhances the late affinity maturation process of human anti-hepatitis B vaccine response. Vaccine. 23:615-622.

59. Cooper, C.L., et al. 2005. CPG 7909 adjuvant improves hepatitis $\mathrm{B}$ virus vaccine seroprotection in antiretroviral-treated HIV-infected adults. AIDS. 19:1473-1479.

60. Cooper, C.L., et al. 2004. Safety and immunogenicity of CPG 7909 injection as an adjuvant to fluarix influenza vaccine. Vaccine. 22:3136-3143.

61. Rosenberg, S.A., Yang, J.C., and Restifo, N.P. 2004. Cancer immunotherapy: moving beyond current vaccines. Nat. Med. 10:909-915.

62. Pulendran, B. and Ahmed, R. 2006. Translating innate immunity into immunological memory: implications for vaccine development. Cell. 124:849-863.

63. Romero, P., et al. 2002. Antigenicity and immunogenicity of Melan-A/MART-1 derived peptides as targets for tumor reactive CTL in human melanoma. Immunol. Rev. 188:81-96.

64. Speiser, D.E., et al. 2003. Evaluation of melanoma vaccines with molecularly defined antigens by ex vivo monitoring of tumor-specific T cells. Semin. Cancer Biol. 13:461-472.

65. Lienard, D., et al. 2006. Ex vivo detectable activation of Melan-A specific T cells correlating with inflammatory skin reactions in melanoma patients vaccinated with peptides in IFA. Cancer Immun. 4:4.

66. Speiser, D.E., et al. 2005. Rapid and strong human CD8(+) $\mathrm{T}$ cell responses to vaccination with peptide, IFA, and CPG oligodeoxynucleotide 7909. J. Clin. Invest. 115:739-746. doi:10.1172/ JCI200523373.

67. Appay, V., et al. 2006. New generation vaccine induces effective melanoma-specific CD8 $+\mathrm{T}$ cells in the circulation but not in the tumor site. J. Immunol. 177:1670-1678.

68. van Ojik, H., et al. 2002. Phase I/II study with CPG 7909 as adjuvant to vaccination with MAGA-3 protein in patients with MAGE-3 positive tumors [abstract]. Ann. Oncol. 13:157.

69. Lonsdorf, A.S., et al. 2003. Intratumor CpGoligodeoxynucleotide injection induces protective antitumor T cell immunity. J. Immunol. 171:3941-3946.

70. Baines, J., and Celis, E. 2003. Immune-mediated tumor regression induced by CpG-containing oligodeoxynucleotides. Clin. Cancer Res. 9:2693-2700.

71. Krieg, A.M. 2004. Antitumor applications of stimulating Toll-like receptor 9 with CPG oligodeoxynucleotides. Curr. Oncol. Rep. 6:88-95.

72. Wooldridge, J.E., Ballas, Z., Krieg, A.M., and Weiner, G.J. 1997. Immunostimulatory oligodeoxynucleotides containing $\mathrm{CPG}$ motifs enhance the efficacy of monoclonal antibody therapy of lymphoma. Blood. 89:2994-2998.

73. Buhtoiarov, I.N., et al. 2006. Synergistic activation of macrophages via CD40 and TLR9 results in T cell independent antitumor effects. J. Immunol. 176:309-318.

74. Vicari, A.P., et al. 2002. Reversal of tumor-induced dendritic cell paralysis by $\mathrm{CPG}$ immunostimulatory oligonucleotide and anti-interleukin 10 receptor antibody. J. Exp. Med. 196:541-549.

75. Guiducci, C., Vicari, A.P., Sangaletti, S., Trinchieri, G., and Colombo, M.P. 2005. Redirecting in vivo elicited tumor infiltrating macrophages and dendritic cells towards tumor rejection. Cancer Res. 65:3437-3446.

76. Dercamp, C., Chemin, K., Caux, C., Trinchieri, G., and Vicari, A.P. 2005. Distinct and overlapping roles of interleukin-10 and CD25+ regulatory $\mathrm{T}$ cells in the inhibition of antitumor CD8 T-cell responses. Cancer Res. 65:8479-8486.

77. Davila, E., Kennedy, R., and Celis, E. 2003. Generation of antitumor immunity by cytotoxic T lymphocyte epitope peptide vaccination, CpG-oligodeoxynucleotide adjuvant, and CTLA4 blockade. Cancer Res. 63:3281-3288.

78. Daftarian, P., et al. 2004. Two distinct pathways of immuno-modulation improve potency of $\mathrm{p} 53$ immunization in rejecting established tumors. Cancer Res. 64:5407-5414.

79. Merad, M., Sugie, T., Engleman, E.G., and Fong, L. 2002. In vivo manipulation of dendritic cells to induce therapeutic immunity. Blood. 99:1676-1682.

80. Okano, F., Merad, M., Furumoto, K., and Engleman, E.G. 2005. In vivo manipulation of dendritic cells overcomes tolerance to unmodified tumorassociated self antigens and induces potent antitumor immunity. J. Immunol. 174:2645-2652.

81. Ishii, K.J., et al. 2003. Antitumor therapy with bacterial DNA and toxin: complete regression of established tumor induced by liposomal CPG oligodeoxynucleotides plus interleukin-13 cytotoxin. Clin. Cancer Res. 9:6516-6522.

82. Chaudhry, U.I., et al. 2006. Combined stimulation with interleukin-18 and CPG induces murine natural killer dendritic cells to produce IFN-gamma and inhibit tumor growth. Cancer Res. 66:10497-10504. 
83. Whitmore, M.M., et al. 2004. Synergistic activation of innate immunity by double-stranded RNA and CPG DNA promotes enhanced antitumor activity. Cancer Res. 64:5850-5860.

84. Sfondrini, L., et al. 2006. Antitumor activity of the TLR-5 ligand flagellin in mouse models of cancer. J. Immunol. 176:6624-6630.

85. Damiano, V., et al. 2006. Novel toll-like receptor 9 agonist induces epidermal growth factor receptor (EGFR) inhibition and synergistic antitumor activity with EGFR inhibitors. Clin. Cancer Res. 12:577-583.

86. Mason, K.A., et al. 2005. Targeting toll-like receptor 9 with CPG oligodeoxynucleotides enhances tumor response to fractionated radiotherapy. Clin. Cancer Res. 11:361-369.

87. Weigel, B.J., Rodeberg, D.A., Krieg, A.M., and Blazar, B.R. 2003. CpG oligodeoxynucleotides potentiate the antitumor effects of chemotherapy or tumor resection in an orthotopic murine model of rhabdomyosarcoma. Clin. Cancer Res. 9:3105-3114.

88. Ohashi, K., et al. 2006. Surgical excision combined with autologous whole tumor cell vaccination is an effective therapy for murine neuroblastoma. J. Pediatr. Surg. 41:1361-1368.

89. den Brok, M.H., et al. 2006. Synergy between in situ cryoablation and TLR9 stimulation results in a highly effective in vivo dendritic cell vaccine. Cancer Res. 66:7285-7292.

90. Taieb, J., et al. 2006. Chemoimmunotherapy of tumors: cyclophosphamide synergizes with exosome based vaccines. J. Immunol. 176:2722-2729.

91. Balsari, A., et al. 2004. Combination of a CpG-oligodeoxynucleotide and a topoisomerase I inhibitor in the therapy of human tumour xenografts. Eur. J. Cancer. 40:1275-1281.

92. Wang, X.S., Sheng, Z., Ruan, Y.B., Guang, Y., and Yang, M.L. 2005. CpG oligodeoxynucleotides inhibit tumor growth and reverse the immunosuppression caused by the therapy with 5 -fluorouracil in murine hepatoma. World J. Gastroenterol. 11:1220-1224.

93. Pratesi, G., et al. 2005. Therapeutic synergism of gemcitabine and $\mathrm{CpG}$-oligodeoxynucleotides in an orthotopic human pancreatic carcinoma xenograft. Cancer Res. 65:6388-6393.

94. Wang, H., et al. 2006. Chemotherapy and chemosensitization of non-small cell lung cancer with a novel immunomodulatory oligonucleotide targeting Toll-like receptor 9. Mol. Cancer Ther. 5:1585-1592.

95. van der Most, R.G., et al. 2006. Antitumor efficacy of the novel chemotherapeutic agent coramsine is potentiated by cotreatment with CpG-containing oligodeoxynucleotides. J. Immunother. 29:134-142.

96. Friedberg, J.W., et al. 2005. Combination immunotherapy with a CpG oligonucleotide (1018 ISS) and rituximab in patients with non-Hodgkin lymphoma: increased interferon-alpha/beta-inducible gene expression, without significant toxicity. Blood. 105:489-495.
97. Jahrsdorfer, B., et al. 2005. Immunostimulatory oligodeoxynucleotides induce apoptosis of B cell chronic lymphocytic leukemia cells. J. Leukoc. Biol. 77:378-387.

98. Jahrsdorfer, B., et al. 2005. B-cell lymphomas differ in their responsiveness to $\mathrm{CPG}$ oligodeoxynucleotides. Clin.Cancer Res. 11:1490-1499.

99. Pashenkov, M., et al. 2006. Phase II trial of a tolllike receptor 9-activating oligonucleotide in patients with metastatic melanoma. J. Clin. Oncol. 24:5716-5724

100.Trefzer, U., et al. 2002. Preliminary results of a phase I trial of intralesional injection of CPG 7909 in patients with basal cell carcinoma or melanoma [abstract]. In 2002 American Society of Clinical Oncology Annual Meeting. 21:1902.

101.Thompson, J.A., Kuxel, T., Bukowski, F., and Schmalbach, T. 2004. Phase Ib trial of a targeted TLR9 CPG immunomodulator (CPG 7909) in advanced renal cell carcinoma (RCC) [abstract]. J. Clin. Oncol. 22:4644.

102.Kim, Y., Girardi, M., McAuley, S., and Schmalbach, T. 2004. Cutaneous T-cell lymphoma (CTCL) responses to a TLR9 agonist $\mathrm{CPG}$ immunomodulator (CPG 7909), a phase I study [abstract]. J. Clin. Oncol. 22:6600.

103.Molenkamp, B.G., et al. 2006. Immunomodulation of the melanoma sentinel lymph node: a novel adjuvant therapeutic option. Immunobiology. 211:651-661.

104. Witt, P.L., et al. 1993. Phase I trial of an oral immunomodulator and interferon inducer in cancer patients. Cancer Res. 53:5176-5180.

105.Machiels, J.P., et al. 2001. Cyclophosphamide, doxorubicin, and paclitaxel enhance the antitumor immune response of granulocyte/macrophagecolony stimulating factor-secreting whole-cell vaccines in HER-2/neu tolerized mice. Cancer Res. 61:3689-3697.

106.Eralp, Y., et al. 2004. Doxorubicin and paclitaxel enhance the antitumor efficacy of vaccines directed against HER 2/neu in a murine mammary carcinoma model. Breast Cancer Res. 6:R275-R283.

107. Nowak, A.K., Robinson, B.W., and Lake, R.A. 2003. Synergy between chemotherapy and immunotherapy in the treatment of established murine solid tumors. Cancer Res. 63:4490-4496.

108. Ghiringhelli, F., et al. 2004. CD4+CD25+ regulatory $\mathrm{T}$ cells suppress tumor immunity but are sensitive to cyclophosphamide which allows immunotherapy of established tumors to be curative. Eur. J. Immunol. 34:336-344.

109.Lutsiak, M.E., et al. 2005. Inhibition of CD4(+)25+ $\mathrm{T}$ regulatory cell function implicated in enhanced immune response by low-dose cyclophosphamide. Blood. 105:2862-2868.

110.Ercolini, A.M., et al. 2005. Recruitment of latent pools of high-avidity CD8(+) T cells to the antitumor immune response. J. Exp. Med. 201:1591-1602.

111.Carson, W.E., 3rd, Shapiro, C.L., Crespin, T.R., Thornton, L.M., and Andersen, B.L. 2004. Cellular immunity in breast cancer patients completing taxane treatment. Clin. Cancer Res. 10:3401-3409.

112.Lake, R.A., and Robinson, B.W. 2005. Immunotherapy and chemotherapy-a practical partnership. Nat. Rev. Cancer. 5:397-405.

113.Emens, L.A., and Jaffee, E.M. 2005. Leveraging the activity of tumor vaccines with cytotoxic chemotherapy. Cancer Res. 65:8059-8064.

114.Chu, Y., et al. 2006. Efficacy of GM-CSF-producing tumor vaccine after docetaxel chemotherapy in mice bearing established Lewis lung carcinoma. J. Immunol. 29:367-380.

115. Obeid, M., et al. 2007. Calreticulin exposure dictates the immunogenicity of cancer cell death. Nat. Med. 13:28-30.

116.Bourquin, C., Schreiber, S., Beck, S., Hartmann, G., and Endres, S. 2006. Immunotherapy with dendritic cells and CpG oligonucleotides can be combined with chemotherapy without loss of efficacy in a mouse model of colon cancer. Int. J. Cancer. 118:2790-2795.

117. Dudley, M.E., et al. 2002. Cancer regression and autoimmunity in patients after clonal repopulation with antitumor lymphocytes. Science. 298:850-854.

118. Correale, P., et al. 2005. Chemo-immunotherapy of metastatic colorectal carcinoma with gemcitabine plus FOLFOX 4 followed by subcutaneous granulocyte macrophage colony-stimulating factor and interleukin-2 induces strong immunologic and antitumor activity in metastatic colon cancer patients. J. Clin. Oncol. 23:8950-8958.

119.Antony, P.A., et al. 2005. CD8+ T cell immunity against a tumor/self-antigen is augmented by CD4+ $\mathrm{T}$ helper cells and hindered by naturally occurring $\mathrm{T}$ regulatory cells. J. Immunol. 174:2591-2601.

120.Beyer, M., et al. 2005. Reduced frequencies and suppressive function of CD4+CD25hi regulatory $\mathrm{T}$ cells in patients with chronic lymphocytic leukemia after therapy with fludarabine. Blood. 106:2018-2025.

121. Manegold, C., et al. 2005. Addition of PF-3512676 (CpG 7909) to a taxane/platinum regimen for first-line treatment of unresectable non-small cell lung cancer (NSCLC) improves objective response phase II clinical trial [abstract]. Eur. J. Cancer. 3:326.

122.Jason, T.L., Koropatnick, J., and Berg, R.W. 2004. Toxicology of antisense therapeutics. Toxicol. Appl. Pharmacol. 201:66-83.

123. Wagner, S., et al. 2006. CPG 7909, a TLR9 agonist immunomodulator in metastatic melanoma: A randomized phase II trial comparing two doses and in combination with DTIC [abstract]. In Journal of Clinical Oncology, 2005 ASCO Annual Meeting Proceedings. 23:7526.

124.Sun, C.M., Deriaud, E., Leclerc, C., and Lo-Man, R 2005. Upon TLR9 signaling, CD5+ B cells control the IL-12-dependent Th1-priming capacity of neonatal DCs. Immunity. 22:467-477.

125.Carpentier, A., et al. 2006. Phase 1 trial of a CpG oligodeoxynucleotide for patients with recurrent glioblastoma. Neuro-oncol. 8:60-66. 